\title{
A dual fracture model to simulate large-scale flow through fractured rocks
}

\author{
E.Z. Wang, Z.Q. Yue, L.G. Tham, Y. Tsui, and H.T. Wang
}

\begin{abstract}
Discrete fracture network models can be used to study groundwater flow in fractured rock masses. However. one may find that it is not easy to apply such models to practical projects as it is difficult to investigate every fracture and measure its hydraulic parameters. To overcome such difficulties, a dual fracture model is proposed. Taking into account the hydraulic characteristics of the various elements of the fracture system, a hydrogeological medium is assumed to consist of two components: the dominant fracture network and the fractured rock matrix. As the dominant fracture network consists of large fractures and faults, it controls the groundwater flow in rock masses. Depending on the permeabilities of the in-fill materials, these fractures and faults may serve as channels or barriers of the flow. The fractured rock matrix, which includes rock blocks and numerous small fractures, plays a secondary role in groundwater flow in such medium. Although the small fractures and rock blocks possess low permeability, their numbers and their total porosity are relatively large. Therefore, they provide large volume for groundwater storage. In this paper, the application of the proposed model to simulate the groundwater flow for a hydropower station before and after reservoir storage is reported. The implications of the results on the design of the station are also highlighted.
\end{abstract}

Key words: seepage flow, dual fracture model, dominant fracture, fractured rock matrix, case studies, rock-filled dam.

Résumé : Des modèles de réseaux de fractures discrètes peuvent être utilisés pour étudier l'écoulcment des eaux souterraines dans les massifs rocheux, mais on peut trouver qu'il n'est pas facile d'appliquer de tels modèles dans des projets pratiques parce qu'il est difficile d'étudier chaque fracture et de mesurer ses paramètres hydrauliques. Afin de surmonter ces difficultés, on propose un modèle à fracturation double. Prenant en compte les caractéristiques hydrauliques des divers éléments du système de fractures, on suppose que le milieu hydro-géologique comprend deux composantes: le réseau de fractures dominantes et la matrice de la roche fracturée. Comme le réseau de fractures dominantes consiste en de larges fractures. il contrôle l'écoulement de l'eau souterraine dans les massifs rocheux. Dépendant des perméabilités des matériaux de remplissage, ces fractures et failles peuvent servir comme des canaux ou des barrières pour l'écoulement. La matrice de roc fracturé qui inclut les blocs de roches et de nombreuses petites fissures joue un rôle secondaire dans l'écoulement de l'eau souterraine dans un tel milieu. Quoique les petites fractures et les blocs de roches possèdent une faible perméabilité, leurs nombres et leur porosité totale sont relativement importants. En conséquence, ils fournissent un grand volume pour l'entreposage de l'eau souterraine. Dans cet article, on fait rapport de l'application du modèle proposé pour simuler l'écoulement de l'eau souterraine pour les centrales hydroélectriques avant et après le remplissage du réservoir. On met aussi en lumière les implications des résultats sur la conception de la centrale.

Mots clés : écoulement d'infiltration, modèle à fracturation double. fracture dominante, matrice de roche fracturée, études de cas, barrages en enrochement.

[Traduit par la Rédaction]

\section{Introduction}

As it is necessary to predict the movement of the ground water for most engineering and hydropower projects, various theories have been developed in recent years to describe seepage in fractured rock masses. Numerous flow models and modeling approaches have been proposed. Mathematical flow models of fractured rocks can be categorized into the following three broad classes (e.g., National Research Council 1996; Singhal and Gupta 1999): (1) equivalent continuum models, (2) discrete network simulation models, and (3) hybrid approaches.

In conventional equivalent continuum models, there are single porosity models (Carrera et al. 1990; Hsieh and Neuman 1985), dual porosity models (Barenblatt et al. 1960; Pruess and Narasimhan 1985; Streltsova 1976), and stochas-

Received 18 September 2001. Accepted 11 June 2002. Published on the NRC Research Press Web site at http://cgj.nrc.ca on 6 November 2002

E.Z. Wang and H.T. Wang. Department of Hydraulic Engineering, Tsinghua University. Beijing, China.

Z.Q. Yue, ${ }^{1}$ L.G. Tham, and Y. Tsui. Department of Civil Engineering, The University of Hong Kong, Pokfulam Road. Hong Kong. China.

${ }^{1}$ Corresponding author (e-mail: yueqzq@ @kucc.hku.hk). 
tic models (Neuman and Depner 1988). As individual fractures are not explicitly modeled, except when the fractures are large enough to be considered as separate hydrological units, these models cannot exactly simulate the behaviour of each fracture. Therefore, the models usually cannot fully describe the hydraulic characteristics of the fractured media.

By assuming that rock masses consist of blocks separated by fractures, the discrete network model treats the fractured rock masses as discontinuous media. The blocks are impermeable, and therefore, groundwater will flow along the fractures. Based on the principle of mass conservation, line element models (Louis and Wittke 1971; Wilson and Witherspoon 1974) were developed to describe the relationship between the hydraulic head and the flux in twodimensional (2D) fracture networks. To provide a systematic means to describe the fracture systems, graph theory was applied to describe the frameworks of fracture networks (Wang 1991; Wang and Yang 1992). Furthermore, 3D flow models of discrete fracture networks have been proposed (Long and Witherspoon 1985; Long et al. 1985; Long and Billaux 1987; Herbert et al. 199I; Dershowitz et al. 1991; Sudicky and McLaren 1992; Wang et al. 1997; Kim and Deo 2000). Although these models can simulate each fracture, they are difficult to use for large-scale problems wherein the rock masses will consist of an enormous amount of fractures. Due to the complexity of fractures, it is difficult, if not impossible, to describe the permeability, orientation, and length of each fracture. If all fractures are included, the models can become very complex. Some efforts have been made to circumvent the above difficulties in defining the fracture systems as regular systems, such as orthogonal fracture systems, parallel plane systems, and stochastic fracture networks (Dershowitz and Einstein 1988; Tsang, et al. 1996). As the permeability of each fracture is one of the input parameters, one may have difficulties in applying such models as the permeability is not necessary known for each fracture.

Such discrete network models can also provide a useful tool for estimating the permeability of a rock mass. Based on a representative unit containing sufficient fractures so that the permeability characteristics of the rock mass can be captured, numerical analyses were carried out to determine the permeabilities of the unit (Long, et al. 1982; Oda 1985; Hsieh and Neuman 1985; Hsieh et al. 1985; Tian and Wan 1989; and Cacas, et al. 1990). The permeability of the rock mass is then assumed to be equal to the permeability of the representative unit and the permeability coefficients thus determined can be used in flow analyses of the rock mass by treating it as a continuum. If the fracture characteristics vary significantly, one can divide the rock mass into a number of zones and the permeability of the representative unit for each zone can be determined. Each zone can then be treated as a continuum with the same permeability as its representative unit. Instead of numerical analysis, Hestir and Long (1990) had also proposed that the permeability of the unit can be obtained by carrying out percolation analysis. An excellent review of these approaches, referred to as the hybrid approaches, can be found in Chapter 6 of a report by the $\mathrm{Na}$ tional Research Council (1996), and readers can refer to it for more details.

If the rock mass contains large fractures, it will be difficult to find an appropriate representative unit simulating the behavior of the rock mass. However, such difficulties can be overcome by using the discrete-continuum approaches (Gomez-Hernandez, et al. 1999; Munjiza, et al. 2000; and Carrera and Lurdes 2000). In these approaches, the dominant fractures were modeled as 2D fractures that were embedded in a 3D porous medium. Wang (1993) had analyzed the 2D groundwater flow problem using a similar concept. Wang et al. (1998) had further developed this model so that it can handle $3 \mathrm{D}$ flow, and they named it the dual fracture model. As in the previous models, the rock masses are assumed to consist of the dominant fracture network and the fractured rock matrix. The dominant fractures were modeled by relatively large fractures as in the discrete approach, whereas the hydraulic properties of the fractured rock matrix were modified to take into account the minor fractures as the continuum approach. In view of the different geometric shapes of the fractures, the dominant fractures were categorized into three groups: pipe-shaped fractures, plane-shaped fractures, and belt-shaped faults. They were modeled by $1 \mathrm{D}$ linear elements, 2D plane elements, and 3D solid elements, respectively.

In the present paper, the applications of the dual fracture model to the analysis of groundwater flow in a hydropower station project in the Nanpanjiang River (NPJ River) in Southwest China are discussed. The applicability of the model is evaluated. Furthermore, the implications of the results on the design of the station are discussed.

\section{Modeling of fractured rock masses by dual fracture model}

Rock masses usually consist of complex fracture systems generated by shrinkage of cooling magma, diagenetic fissures of sedimentary rocks, cleavage of metamorphic rocks, bedding plane foliates, tectonic joints, shear zones, dykes, weathering fractures, unloading fractures, cavities and cracks, etc. The fractures are of different sizes and extents. Large fractures, such as faults, large joints or fissures, shear zones, dykes, and bedding plane foliates can be of several hundred metres or kilometres in strike length. They constitute the main framework of the fracture system. Most of the fractures have high permeability and serve as conduits for the groundwater flow. However, there are fractures, such as compression faults and fissures, as well as faults with in-fill of low permeability that will form barriers to the groundwater flow. Nevertheless, these large fractures play predominant roles, either as conduits or barriers, in determining the flow of groundwater, and they are referred to as dominant fracture networks. These dominant fractures divide the rock mass into blocks (fractured rock matrices) that still contain small fractures and pores. These fractures and pores are small in size, but they are present in large numbers. Therefore, a large volume of groundwater can be stored in the spaces created by the fractures. It is also observed that water will flow into and out of the fractured rock matrices through the dominant fractures as water is pumped into and out of the rock masses (Fig. 1). In view of the fact that the dominant fracture networks and fractured rock matrices play different roles in controlling the movement of groundwater within the rock masses, the dual fracture model was developed to simulate their behaviors. 
Fig. 1. Schematic diagram of a dual fracture system.

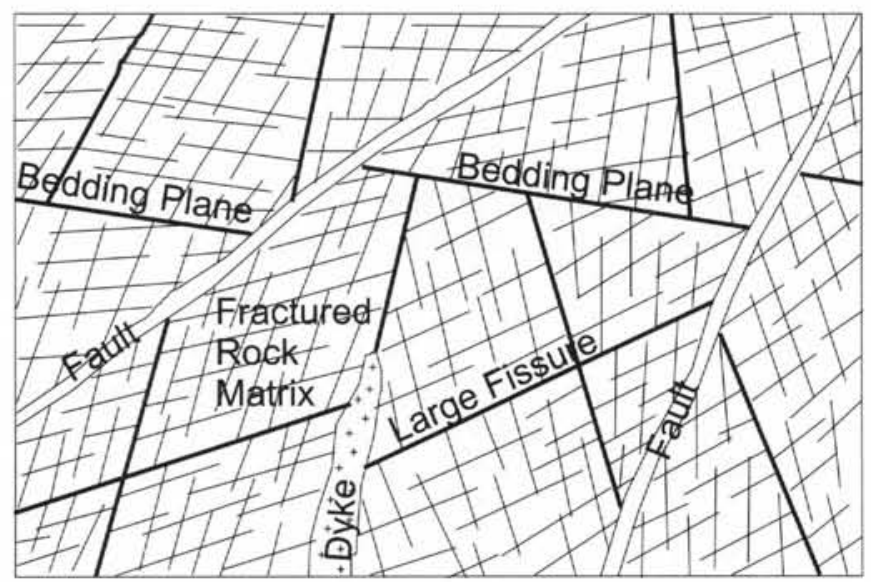

\section{Flow model of dominant fracture networks}

According to their seepage characteristics and structural geometry, the following three types of dominant fractures are identified:

(1) pipe-shaped structures, such as solution cavities, burrows, man-made orifices, etc.;

(2) plane-shaped fractures, such as large fissures of different mechanical characteristics, bedding planes, disorder fractures between geological strata, etc.;

(3) belt-shaped faults, such as different kinds of ruptures, faults, rock dykes, broken cleavages, and shear zones, etc.

These three types of structures connect with each other in the form of $1 \mathrm{D}, 2 \mathrm{D}$, and $3 \mathrm{D}$ elements, respectively, so that a 3D dominant fractured network is formed. Based on the geometrical configurations of these three types of fractures, a flow equation for each type is derived.

A pipe-shaped structure will be separated into several segments by other fractures (Fig. $2 a$ ), and each segment can be represented by a line element. The groundwater will flow along the structures. Assuming Darcy's Law, the flow equation, in local coordinate $\left(x^{\prime}\right)$, can be written as

$$
\frac{\partial}{\partial x^{\prime}}\left(K_{\mathrm{x}^{\prime}} \frac{\partial H_{\mathrm{f}}}{\partial x^{\prime}}\right)+Q_{\mathrm{f}}=S_{\mathrm{f}} \frac{\partial H_{\mathrm{f}}}{\partial t}
$$

where $H_{\mathrm{f}}$ is the total head, $Q_{\mathrm{f}}$ is the volume of flux per unit volume (inflow or outflow), $K_{\mathrm{x}^{\prime}}$ is the coefficient of permeability in the $x^{\prime}$ direction, $S_{\mathrm{f}}$ is the specific storage, and $t$ is the time. The subscript $f$ implies fracture.

A plane-shaped fracture can be separated into several plane polygons by other fractures (Fig. $2 b$ ). In such fractures, the groundwater flow is $2 \mathrm{D}$ within the fracture plane. In the local coordinate $\left(x^{\prime}, y^{\prime}\right)$, the flow equation is written as

$$
\frac{\partial}{\partial x^{\prime}}\left(K_{\mathrm{x}^{\prime}} \frac{\partial H_{\mathrm{f}}}{\partial x^{\prime}}\right)+\frac{\partial}{\partial y^{\prime}}\left(K_{\mathrm{y}^{\prime}} \frac{\partial H_{\mathrm{f}}}{\partial y^{\prime}}\right)+Q_{\mathrm{f}}=S_{\mathrm{f}} \frac{\partial H_{\mathrm{f}}}{\partial t}
$$

where $K_{y^{\prime}}$ is the coefficient of permeability in the $y^{\prime}$ direction.

A typical belt-shaped fault can be divided into fault core and damage zones. The fault core consists primarily of breccia and other cataclastic rocks, whereas the damage zone contains numerous fractures. For a major fault zone, the fault core thickness can be up to several tens of metres, and the damage zone thickness can be several hundred metres. As dykes consist of dyke cores and damage zones, they can also be modeled as belt-shaped faults. A belt shaped fault or dyke can be divided into several flat polyhedrons by other fractures or structures (Fig. 2c). In each of these polyhedrons, the flow will be $3 \mathrm{D}$ and the flow equation

$$
\begin{array}{r}
\frac{\partial}{\partial x^{\prime}}\left(K_{\mathrm{x}^{\prime}} \frac{\partial H_{\mathrm{f}}}{\partial x^{\prime}}\right)+\frac{\partial}{\partial y^{\prime}}\left(K_{\mathrm{y}^{\prime}} \frac{\partial H_{\mathrm{f}}}{\partial y^{\prime}}\right)+\frac{\partial}{\partial z^{\prime}}\left(K_{\mathrm{z}^{\prime}} \frac{\partial H_{\mathrm{f}}}{\partial z^{\prime}}\right) \\
+Q_{\mathrm{f}}=S_{\mathrm{f}} \frac{\partial H_{\mathrm{f}}}{\partial t}
\end{array}
$$

where $K_{\mathrm{z}}$ is the coefficient of permeability of the fracture in the $z^{\prime}$ direction. Note that the coordinates $\left(x^{\prime}, y^{\prime}, z^{\prime}\right)$ are chosen in such a way that the axes are along the principal directions of permeability.

Following the standard procedures of the finite element method, the three different forms of fractures can be modeled by linear, plane (triangular or quadrilateral), and solid (tetrahedron or hexahedron) elements. The flow equations can be easily written in matrix form and they can be combined together to obtain the flow equation for the network

$$
[G]\left[H_{\mathrm{f}}\right]+[W]+\left[D_{\mathrm{f}}\right]\left[\frac{\mathrm{d} H_{\mathrm{f}}}{\mathrm{d} t}\right]=\left[E_{\mathrm{f}}\right]
$$

where $[G]$ is the permeability matrix of the dominant fracture network; $[W]$ is the water exchange matrix between the dominant fracture network and the fractured rock matrix; $\left[D_{\mathrm{f}}\right]$ is the water storage coefficient matrix of the dominant fracture network; $\left[H_{\mathrm{f}}\right]$ is the hydraulic head vector of the dominant fracture network; and $\left[E_{\mathrm{f}}\right]$ is the source and sink matrix of the dominant fracture network.

\section{Flow equation for fractured rock matrix}

The fractured rock matrix consists not only of small fractures but it also contains pores. For each fractured rock matrix, a geological statistical method can be used to determine the hydraulic parameters (such as the width, position, density, communicating ratio of fracture, etc.) of the visible fractures in a fractured rock matrix. The permeability tensor $(K)$ reflecting the continuum properties of the fractured rock matrix can be obtained. (Long et al. 1982; Oda 1985; Hsieh and Neuman 1985; Hsieh et al. 1985; Tian and Wan 1989; Cacas et al. 1990).

For any fractured rock matrix, the governing equation for the groundwater flow can be described as

$$
\begin{array}{r}
\frac{\partial}{\partial x^{\prime}}\left(K_{\mathrm{x}^{\prime}} \frac{\partial H_{\mathrm{s}}}{\partial x^{\prime}}\right)+\frac{\partial}{\partial y^{\prime}}\left(K_{\mathrm{y}^{\prime}} \frac{\partial H_{\mathrm{s}}}{\partial y^{\prime}}\right)+\frac{\partial}{\partial z^{\prime}}\left(K_{\mathrm{z}^{\prime}} \frac{\partial H_{\mathrm{s}}}{\partial z^{\prime}}\right) \\
+Q_{\mathrm{s}}=S_{\mathrm{s}} \frac{\partial H_{\mathrm{s}}}{\partial t}
\end{array}
$$

where $K_{x^{\prime}}, K_{y^{\prime}}$, and $K_{z^{\prime}}$ are the coefficients of permeability $(K)$ along the three principal directions. The subscript $s$ implies the fractured rock matrix.

Since fractured rock matrices are surrounded by a dominant fracture network, the hydraulic head of the dominant fracture network along fracture walls can be used as the 
Fig. 2. Schematic diagram of different types of fractures $(a)$ pipe-shaped structure; $(b)$ plane-shaped fracture; $(c)$ belt-shaped fault.

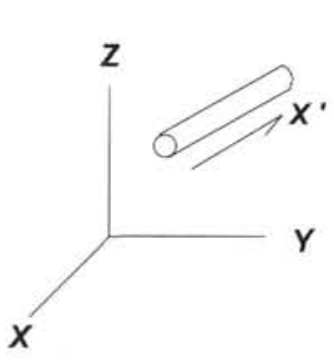

(a)

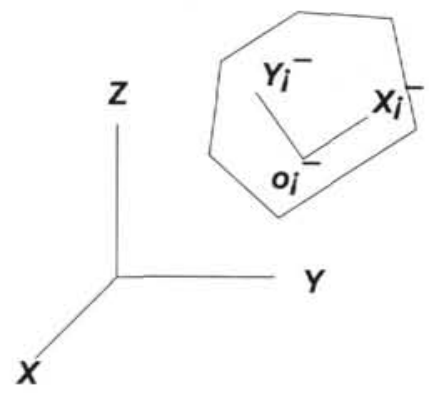

(b)

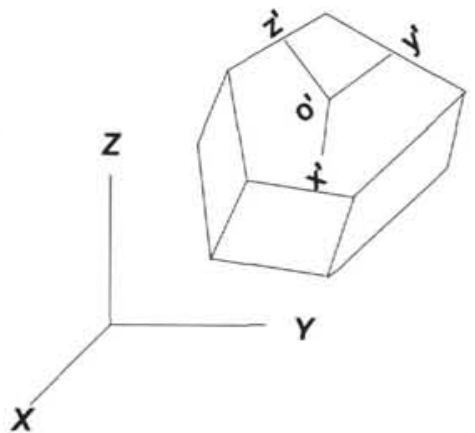

(c)

boundary conditions of the fractured rock matrix bound by the fracture walls. The flow equation for a fractured rock matrix can be written as

$$
\left[R_{\mathrm{s}}\right]_{k}\left[H_{\mathrm{s}}\right]_{k}+\left[D_{\mathrm{s}}\right]_{k}\left[\frac{\mathrm{d} H_{\mathrm{s}}}{\mathrm{d} t}\right]_{k}=\left[E_{\mathrm{s}}\right]_{k}
$$

where $\left[R_{\mathrm{s}}\right]$ is the permeability matrix of the fractured rock matrix; $\left[D_{\mathrm{s}}\right]$ is the water storage matrix; and $\left[E_{\mathrm{s}}\right]$ is the source and sink quantity. The subscript $k$ is the number of the fractured rock matrix.

\section{Combined flow model}

The water exchange term between the fracture matrix blocks and the dominant fracture network can be described in terms of the normal flow rate across the circumference of the fracture matrix blocks. Each fracture of the dominant fracture network will exchange water with the fractured rock matrix. Therefore, the water exchange term of eq. [4] can be expressed as

$$
[W]=\left[R_{\mathrm{f}}\right]\left[H_{\mathrm{f}}\right]+\left[R_{\mathrm{s}}\right]_{\mathrm{f}}\left[H_{\mathrm{s}}\right]_{\mathrm{f}}
$$

where the subscript $f$ of $\left[R_{\mathrm{s}}\right]_{\mathrm{f}}$ and $\left[H_{\mathrm{s}}\right]_{\mathrm{f}}$ stands for the elements connecting the fractured rock matrix with the dominant fracture network.

Combining the above equations, we have the seepage flow model in a dual fracture system as

$$
\left[G_{\mathrm{f}}\right]\left[H_{\mathrm{f}}\right]+\left[R_{\mathrm{s}}\right]_{\mathrm{f}}\left[H_{\mathrm{s}}\right]_{\mathrm{f}}+\left[D_{\mathrm{f}}\right]\left[\frac{\mathrm{d} H_{\mathrm{f}}}{\mathrm{d} t}\right]=\left[E_{\mathrm{f}}\right]
$$

$$
\left[R_{\mathrm{f}}\right]_{k}\left[H_{\mathrm{f}}\right]_{k}+\left[R_{\mathrm{s}}\right]_{k}\left[H_{\mathrm{s}}\right]_{k}+\left[D_{\mathrm{s}}\right]_{k}\left[\frac{\mathrm{d} H_{\mathrm{s}}}{\mathrm{d} t}\right]_{k}=\left[E_{\mathrm{s}}\right]_{k}
$$

where $\left[G_{\mathrm{f}}\right]=[G]+\left[R_{\mathrm{f}}\right]$, and $k=1,2, \ldots, m(m$ is the total number of the fractured rock matrix blocks).

Finally, eq. [8] can be written as

[9a]

$$
[T][H]+[D]\left[\frac{\mathrm{d} H}{\mathrm{~d} t}\right]=[E]
$$

in which,
$[9 b] \quad[T]=\left[\begin{array}{cc}{\left[G_{\mathrm{f}}\right]} & {\left[R_{\mathrm{s}}\right]_{\mathrm{f}}} \\ {\left[R_{\mathrm{f}}\right]_{1}} & {\left[R_{\mathrm{s}}\right]_{1}} \\ {\left[R_{\mathrm{f}}\right]_{2}} & {\left[R_{\mathrm{s}}\right]_{2}} \\ \vdots & \vdots \\ {\left[R_{\mathrm{f}}\right]_{m}} & {\left[R_{\mathrm{s}}\right]_{m}}\end{array}\right]$
$[H]=\left[\begin{array}{c}{\left[H_{\mathrm{f}}\right]} \\ {\left[H_{\mathrm{s}}\right]_{1}} \\ {\left[H_{\mathrm{s}}\right]_{2}} \\ \vdots \\ {\left[H_{\mathrm{s}}\right]_{m}}\end{array}\right]$
$[D]=\left[\begin{array}{c}{\left[D_{\mathrm{f}}\right]} \\ {\left[D_{\mathrm{s}}\right]_{1}} \\ {\left[D_{\mathrm{s}}\right]_{2}} \\ \vdots \\ {\left[D_{\mathrm{s}}\right]_{m}}\end{array}\right]$
$[E]=\left[\begin{array}{c}{\left[E_{\mathrm{f}}\right]} \\ {\left[E_{\mathrm{s}}\right]_{1}} \\ {\left[E_{\mathrm{s}}\right]_{2}} \\ \vdots \\ {\left[E_{\mathrm{s}}\right]_{m}}\end{array}\right]$

Imposing the hydraulic boundary conditions, eq. [9] can be solved to obtain the hydraulic head at each node.

\section{General conditions of Tianshengqiao Hydropower Station}

\section{Geological conditions}

The Tianshengqiao Hydropower Station is located in the Nanpanjiang River (NPJ River) in Southwest China. The station, which has a capacity of $1200 \mathrm{MW}$, consists of a rockfilled dam with a reinforcement face slab, a spillway on the right bank, and a diversion tunnel on the left bank. The dam is $178 \mathrm{~m}$ high and is ranked first in height in China and second in the world in its category. Its crest length is $1104 \mathrm{~m}$.

The bedrock at two abutments of the dam site consists of sedimentary sandstone, sedimentary mudstone, and thick to thin layer limestone of Middle Triassic stratum formation (Fig. 3). Faults $F_{1}$ and $F_{8}$ at the right bank are the major geological structures dominating the distribution of groundwater in the area of the dam. The fault zones of $F_{1}$ and $F_{8}$ range from several metres to nearly $100 \mathrm{~m}$ in width. Their lengths are over $10 \mathrm{~km}$. Faults $F_{10}, F_{11}, F_{12}, F_{15}$, and $F_{17}$ at the right bank as well as $F_{16}$ and $F_{20}$ at the left bank are the secondary structures with widths of several metres and lengths varying from several hundred metres to $1500 \mathrm{~m}$. These large faults, depending on their permeabilities, serve as the main conduits or barriers for the flow of groundwater, and they are regarded as the dominant fracture network. 
Fig. 3. Map of the geological structures and building position in the area of the dam of Tianshengqiao Hydropower Station.

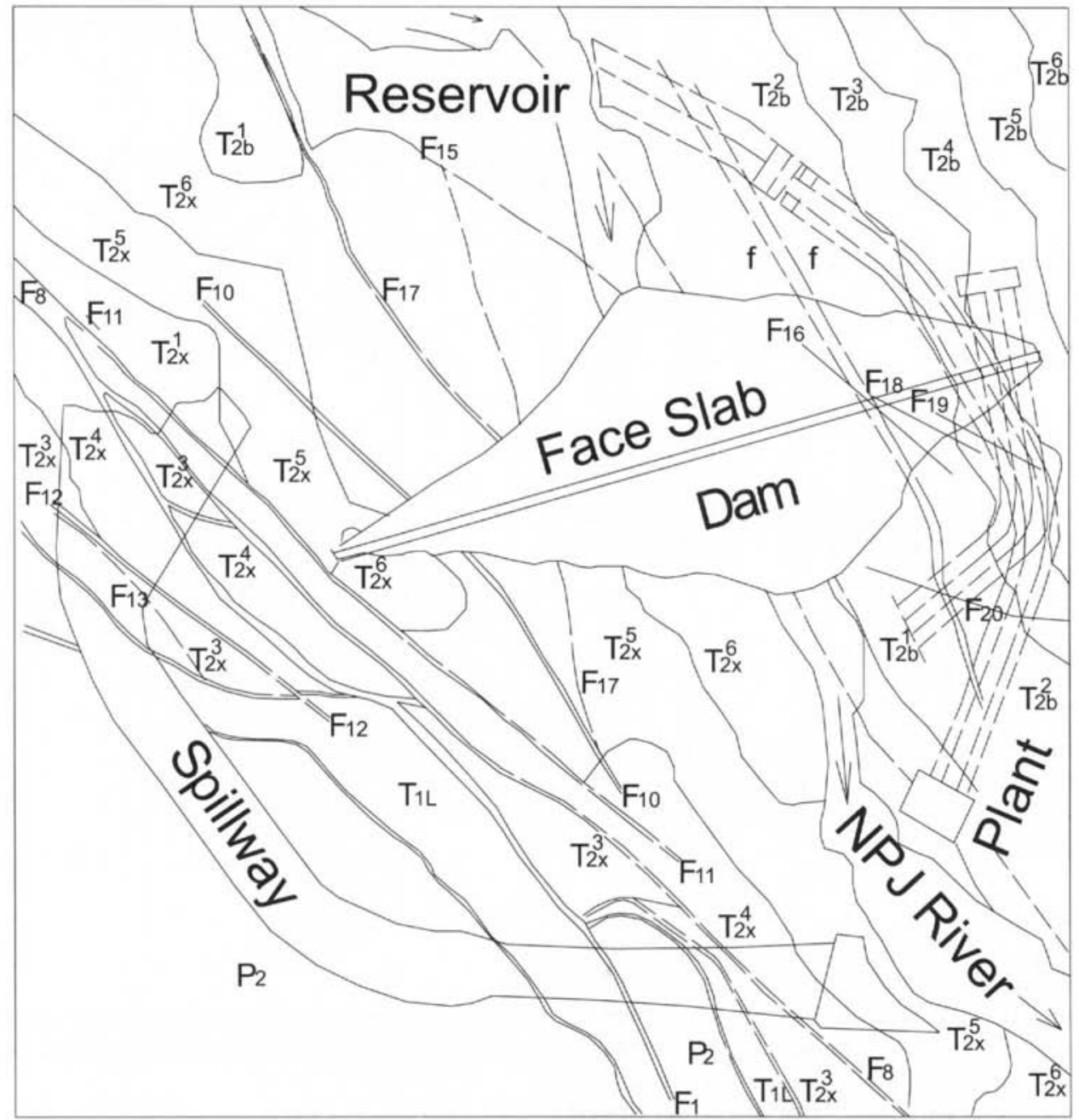

Fig. 4. Three-dimensional discrete elements of the analysis domain.

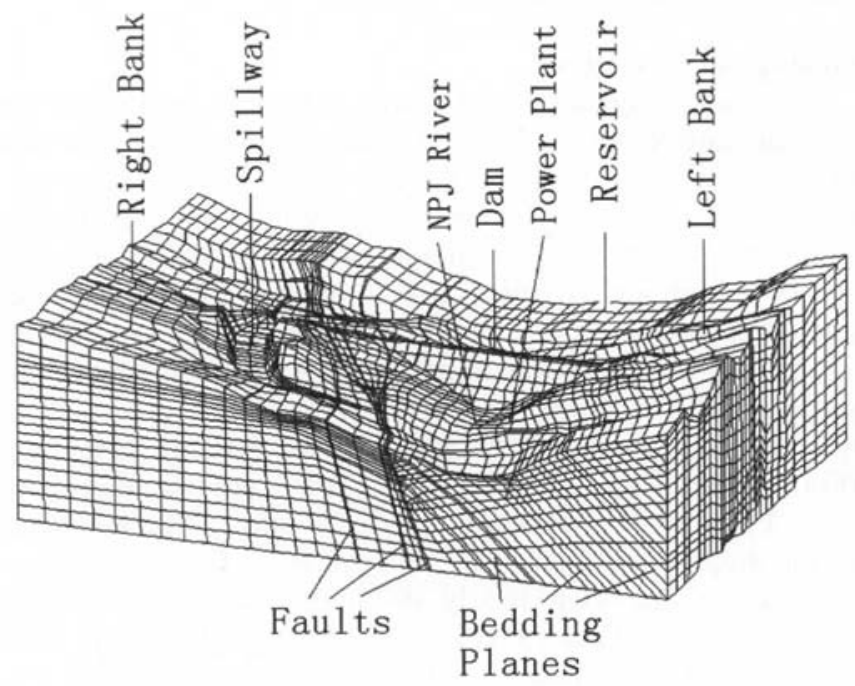

These faults divide the bedrock into a large number of fractured rock matrix blocks. In each of these blocks, there are numerous minor fractures and pores. Due to low permeability, the flow of groundwater in these blocks is not as fast as in the dominant fractures. However, the pores and minor fractures can store a large volume of water. In the analysis, they are treated as a continuum that has hydraulic properties modified to take into account the fractures and the pores.

\section{Discrete elements of 3D seepage analysis}

Figure 4 shows the 3D model adopted for the analysis. The domain is $2800 \mathrm{~m} \times 2055 \mathrm{~m} \times 600 \mathrm{~m}$ in size, and it is discretized into 24012 elements with 26430 nodes. The model includes the major geological formations (Fig. 3) including $\mathrm{P}_{2}, \mathrm{~T}_{1 \mathrm{~L}}, \mathrm{~T}_{2 \mathrm{x}}{ }^{3}, \mathrm{~T}_{2 \mathrm{x}}{ }^{4}, \mathrm{~T}_{2 \mathrm{x}}{ }^{5}, \mathrm{~T}_{2 \mathrm{x}}{ }^{6}, \mathrm{~T}_{2 \mathrm{~b}}{ }^{1}, \mathrm{~T}_{2 \mathrm{~b}}{ }^{2}, \mathrm{~T}_{2 \mathrm{~b}}{ }^{3}, \mathrm{~T}_{2 \mathrm{~b}}{ }^{4}, \mathrm{~T}_{2 \mathrm{~b}}{ }^{5}$, $\mathrm{T}_{2 \mathrm{~b}}{ }^{6}, \mathrm{~T}_{2 \mathrm{~b}}{ }^{7}$. Furthermore, all major and secondary geological structures (Fig. 3) are modeled. They include faults $F_{1}, F_{10}$, $F_{11}, F_{12}, F_{15}, F_{16}, F_{17}, F_{20}$, the fault core of $F_{8}\left(F_{8}-c\right)$, the effective zones of $\mathrm{F}_{8}\left(\mathrm{~F}_{8}-\mathrm{e}\right)$, and the bedding planes among the layers, which covers most of the big and subordinate faults. Minor geological structures are included if they are considered to have some effect on the groundwater flow. More details of the geological formations can be found in the project report (Tsinghua University 1998).

Structures such as the dam, the impervious curtain, the drain channel, and the structures built at the downstream of the dam for collecting seepage flow, are all included in the analyses. 
Table 1. The permeability coefficients of some layers and main faults.

\begin{tabular}{|c|c|c|c|c|c|c|c|}
\hline \multirow[b]{2}{*}{ Formation } & \multirow[b]{2}{*}{$\begin{array}{l}\text { Field } K^{0} \\
(\mathrm{~m} / \text { day })\end{array}$} & \multicolumn{3}{|c|}{ Permeability tensor (m/day) } & \multicolumn{3}{|c|}{ Calibrated permeability (m/day) } \\
\hline & & $K_{\mathrm{x}^{\prime}}$ & $K_{y^{\prime}}$ & $K_{z^{\prime}}$ & $K_{\mathrm{x}^{\prime}}$ & $K_{y^{\prime}}$ & $K_{z^{\prime}}$ \\
\hline $\mathrm{P}_{2}$ & 0.2745 & 5.8870 & 1.3486 & 4.3404 & 0.4966 & 0.1138 & 0.3661 \\
\hline $\mathrm{T}_{1 \mathrm{~L}}$ & 0.0825 & 1.4674 & 0.4671 & 0.7863 & 0.1488 & 0.0474 & 0.0797 \\
\hline$T_{2 x}{ }^{4}$ & 0.1296 & 0.8183 & 0.3102 & 0.6170 & 0.1967 & 0.0746 & 0.1483 \\
\hline$T_{2 x^{5}}$ & 0.2280 & 1.8648 & 0.6148 & 1.2891 & 0.3733 & 0.1231 & 0.2580 \\
\hline$T_{2 x}{ }^{6}$ & 0.4995 & 3.3118 & 1.2746 & 2.6634 & 0.7384 & 0.2842 & 0.5938 \\
\hline $\mathrm{T}_{2 \mathrm{~b}}{ }^{1}$ & 0.2640 & 1.6631 & 0.6537 & 0.9535 & 0.4338 & 0.1705 & 0.2487 \\
\hline $\mathrm{T}_{2 \mathrm{~b}}{ }^{2}$ & 0.1995 & 0.9199 & 0.3014 & 0.4236 & 0.3747 & 0.1228 & 0.1726 \\
\hline $\mathrm{T}_{2 \mathrm{~b}}{ }^{3}$ & 0.1635 & 3.7551 & 1.0418 & 1.7460 & 0.3236 & 0.0898 & 0.1505 \\
\hline $\mathrm{T}_{2 \mathrm{~b}}{ }^{4}$ & 0.4605 & 5.4430 & 1.1215 & 3.7948 & 0.8793 & 0.1812 & 0.6130 \\
\hline $\mathrm{T}_{2 \mathrm{~b}}{ }^{5}$ & 0.2175 & 2.1366 & 0.6127 & 0.9059 & 0.4384 & 0.1257 & 0.1859 \\
\hline \multicolumn{8}{|c|}{ (b) Major and secondary geological structures. } \\
\hline \multirow[b]{2}{*}{ Fault } & \multirow[b]{2}{*}{$\begin{array}{l}\text { Field } K^{0} \\
(\mathrm{~m} / \text { day) }\end{array}$} & \multicolumn{3}{|c|}{ Permeability ratio } & \multicolumn{3}{|c|}{ Calibrated permeability (m/day) } \\
\hline & & $r_{1}$ & $r_{2}$ & $r_{3}$ & $K_{\mathrm{x}^{\prime}}$ & $K_{y^{\prime}}$ & $K_{z^{\prime}}$ \\
\hline $\mathrm{F}_{8}-\mathrm{c}$ & 0.0003 & 1.25 & 1.333 & 1.667 & 0.00048 & 0.00032 & 0.00024 \\
\hline $\mathrm{F}_{8}-\mathrm{e}$ & 0.0005 & 1.25 & 1.333 & 1.667 & 0.00069 & 0.00046 & 0.00035 \\
\hline $\mathrm{F}_{10}$ & 1.2960 & 1.25 & 1.333 & 1.667 & 1.86900 & 1.24600 & 0.93473 \\
\hline $\mathrm{F}_{11}$ & 1.0370 & 1.25 & 1.333 & 1.667 & 1.49549 & 0.99699 & 0.74793 \\
\hline$F_{12}$ & 0.7760 & 1.25 & 1.333 & 1.667 & 1.11909 & 0.74606 & 0.55969 \\
\hline$F_{15}$ & 0.7760 & 1.25 & 1.333 & 1.667 & 1.11909 & 0.74606 & 0.55969 \\
\hline $\mathrm{F}_{20}$ & 1.2960 & 1.25 & 1.333 & 1.667 & 1.86900 & 1.24600 & 0.93473 \\
\hline
\end{tabular}

(c) Engineering structures.

\begin{tabular}{llll}
\hline \multirow{2}{*}{ Zone } & \multicolumn{2}{l}{ Permeability $(\mathrm{m} /$ day $)$} \\
\cline { 2 - 4 }$K_{1}$ & $K_{2}$ & $K_{3}$ \\
\hline Dam-I & $0.216 \times 10^{2}$ & $0.216 \times 10^{2}$ & $0.864 \times 10^{1}$ \\
Dam-II & $0.218 \times 10^{4}$ & $0.218 \times 10^{4}$ & $0.872 \times 10^{3}$ \\
Dam-III & $0.720 \times 10^{4}$ & $0.720 \times 10^{4}$ & $0.288 \times 10^{4}$ \\
Face slab & $0.864 \times 10^{-4}$ & $0.864 \times 10^{-4}$ & $0.864 \times 10^{-4}$ \\
Grout curtain & $0.864 \times 10^{-2}$ & $0.864 \times 10^{-2}$ & $0.864 \times 10^{-2}$ \\
Other & $0.864 \times 10^{-3}$ & $0.864 \times 10^{-3}$ & $0.864 \times 10^{-3}$ \\
\hline
\end{tabular}

\section{Boundary conditions}

As the dam is built across a river with high mountain ridges on both banks, there are six boundaries for the domain adopted in the analyses. They are

- the upstream boundaries,

- the downstream boundaries,

- the right side boundaries,

- the left side boundaries,

- the bottom boundary, and

- the ground surface boundary.

The upstream and downstream boundaries are vertical boundaries at the two ends of the model and perpendicular to the mountain ridges. They are approximately parallel to the groundwater flow direction from the mountain ridges toward the river valley in natural conditions (Fig. 4). After reservoir storage, water will infiltrate vertically along these boundaries. Therefore, the boundaries can be considered to be streamlines.

The right and left side boundaries are nearly along the watersheds of the mountain ridges at two sides of the valley, and therefore, can be approximately regarded as no-flow boundaries. The bottom of the model is nearly parallel to the groundwater streamlines, therefore it can also be considered to be a no-flow boundary.

The ground surface can be divided into two parts. The first part consists of areas that are below the river or reservoir water level. As they are under the surface water, the head will be the river or reservoir water levels. Therefore, they can be taken to be constant hydraulic head boundaries. The second part consists of the ground surfaces above the water level of the river on both sides of the river valley. Rainfall infiltration can take place. By assuming infiltration coefficients and rainfall intensity of this boundary, groundwater distribution of the conditions of both nature and reservoir storage can be simulated and the corresponding seepage flow can be calculated.

\section{Permeability coefficients}

In the analyses, one has to assign permeability coefficients for each of the geological formations and structures. The ac- 
Fig. 5. Contours of the measured natural groundwater levels in dry season before impounding water in the reservoir.

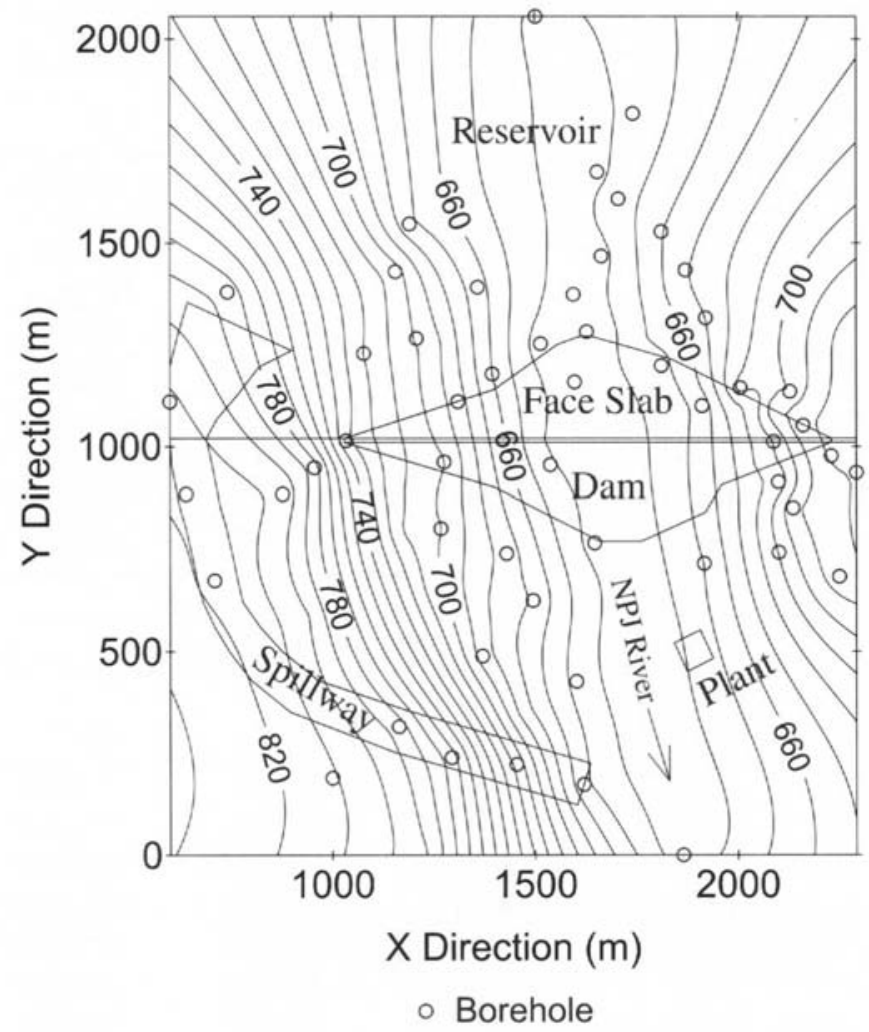

Fig. 6. Contours of the calculated groundwater levels in dry season before impounding water in the reservoir.

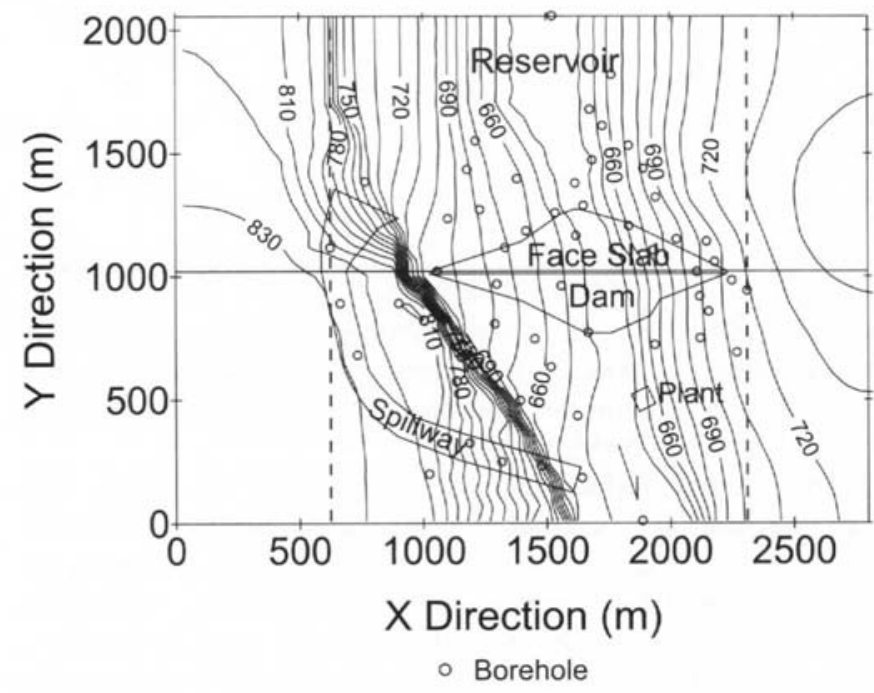

curacy of the analysis results will depend very much on these coefficients. As the permeability coefficients determined in the laboratory tests may not reflect the field permeability due to the scale effect, the permeability coefficients are determined by using field pumping tests and well water injection tests. However, these tests can only yield an isotropic permeability coefficient, which cannot reflect the anisotropic nature of the geological structures and formations. In the present paper, an approximate means to estimate the
Fig. 7. Contours of the computed groundwater surface during dry season at a high water level in the reservoir.

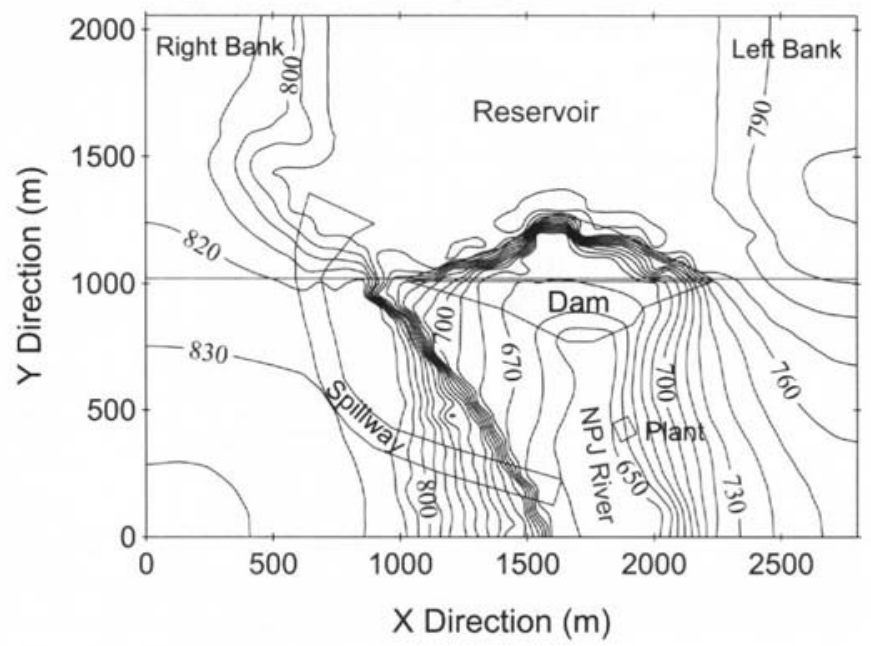

Table 2. Comparison between predicted and observed groundwater levels.

\begin{tabular}{lllc}
\hline & $\begin{array}{l}\text { Observed } \\
\text { groundwater } \\
\text { level }(\mathrm{m})\end{array}$ & $\begin{array}{l}\text { Predicted } \\
\text { groundwater } \\
\text { level }(\mathrm{m})\end{array}$ & $\begin{array}{l}\text { Difference between } \\
\text { observed and } \\
\text { predicted levels }(\mathrm{m})\end{array}$ \\
$\begin{array}{l}\text { Borehole } \\
\text { number }\end{array}$ & (A) & $(\mathrm{B})$ & $(=\mathrm{A}-\mathrm{B})$ \\
\hline HW9 & 771.44 & 764.28 & 7.16 \\
HW63 & 737.61 & 729.54 & 8.07 \\
HW105 & 700.72 & 697.36 & 3.36 \\
HW258 & 777.80 & 771.53 & 6.27 \\
HW259 & 778.36 & 764.84 & 13.52 \\
HW260 & 790.73 & 786.42 & 4.31 \\
HW261 & 779.58 & 766.86 & 12.72 \\
HW262 & 768.38 & 760.73 & 7.65 \\
HW263 & 735.42 & 734.17 & 1.25 \\
HW251 & 778.68 & 774.34 & 4.34 \\
HW252 & 779.63 & 772.86 & 6.77 \\
HW253 & 773.27 & 769.48 & 3.79 \\
HW254 & 779.16 & 767.57 & 11.59 \\
HW255 & 773.49 & 762.28 & 11.21 \\
HW256 & 775.44 & 763.46 & 11.98 \\
HW257 & 712.91 & 714.63 & -1.72 \\
\hline
\end{tabular}

principal permeability coefficients from the field tests and geological statistical data is proposed.

Assuming the permeability coefficient for a certain geological formation is determined to be $K^{0}$ from the field test data, the spatial variation of the permeability can be described by a sphere with $K^{0}$ as the radius if the formation is isotropic.

As the formation is usually anisotropic in nature, one can assume the variation of the permeability coefficient can be described by an ellipsoid. The directions of the principal coefficients will be determined by the aperture, density, length, and orientation of the fractures (Oda 1985). Such information can be obtained by carrying out geological surveys. Furthermore, one can determine the ratios among three principal permeability coefficients from such information, that is 
Fig. 8. Estimated level of the groundwater in the dam and downstream river for a high water level (H.W.L.) in the reservoir at the upstream of the dam.

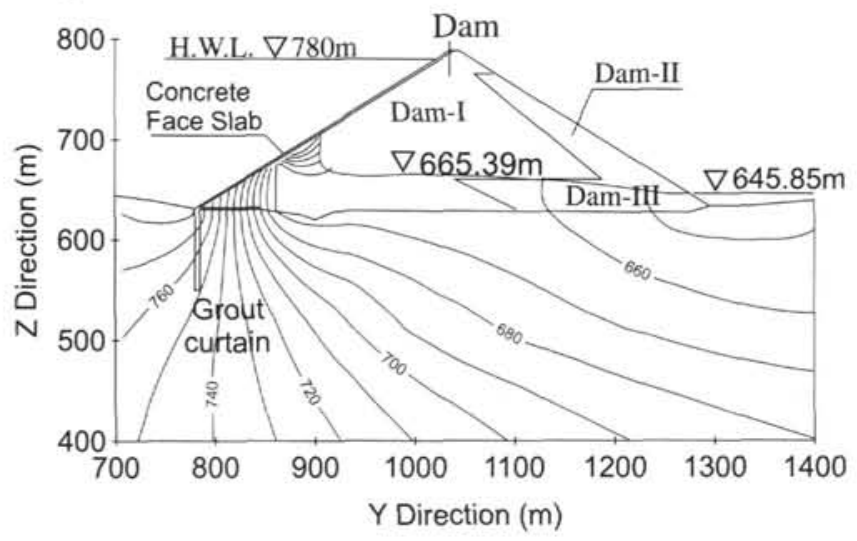

Table 3. Comparison between predicted and observed values of leakage flux $\left(\mathrm{m}^{3} / \mathrm{s}\right)$

\begin{tabular}{|c|c|c|c|c|}
\hline Location & $\begin{array}{l}\text { Drainage } \\
\text { collection } \\
\text { in dam } \\
\text { body }\end{array}$ & $\begin{array}{l}\text { No. } 3 \\
\text { drainage } \\
\text { cavity in } \\
\text { right bank }\end{array}$ & $\begin{array}{l}\text { No. } 7 \\
\text { drainage } \\
\text { cavity in } \\
\text { right bank }\end{array}$ & $\begin{array}{l}\text { Hillside } \\
\text { behind } \\
\text { the plant }\end{array}$ \\
\hline Predicted & $0.117 \sim 0.387$ & 0.000643 & 0.000242 & 0.00136 \\
\hline $\begin{array}{l}\text { Observed } \\
\text { (A) }\end{array}$ & 0.13238 & 0.000280 & 0.000510 & 0.00183 \\
\hline $\begin{array}{l}\text { Observed } \\
\text { (B) }\end{array}$ & 0.16519 & 0.000220 & 0.000570 & 0.00217 \\
\hline
\end{tabular}

$$
\begin{aligned}
& {[10 a] \frac{K_{\mathrm{x}^{\prime}}}{K_{\mathrm{y}^{\prime}}}=r_{\mathrm{i}}} \\
& {[10 b] \frac{K_{\mathrm{y}^{\prime}}}{K_{\mathrm{z}^{\prime}}}=r_{2}}
\end{aligned}
$$

In the proposed approach, it is further assumed that the volume of the sphere and the ellipsoid representing the variation of the permeability should be equal.

Therefore, one can show readily that

$$
\begin{aligned}
& {[11 a] \quad K_{\mathrm{x}^{\prime}}=\sqrt[3]{r_{1}^{2} r_{2}} K^{0}} \\
& {[11 b] \quad K_{\mathrm{y}^{\prime}}=\sqrt[3]{\frac{r_{2}}{r_{\mathrm{f}}}} K^{0}} \\
& {[11 c] \quad K_{\mathrm{z}^{\prime}}=\sqrt[3]{\frac{1}{r_{1}^{2} r_{2}^{2}}} K^{0}}
\end{aligned}
$$

A similar approach can be used to determine the principal permeability coefficients for faults. The three principal directions of permeability are assumed as follows: the first one is along the movement direction of the fault plane, the second is also along the fault plane but perpendicular to the first one, and the third is along the dip direction of the fault (orthogonal to the fault plane). In this paper, the ratios of the three principal permeability coefficients are based on past experience.
Based on the above approach, permeability coefficients are obtained from the results of the field tests and geological statistics of the fractures. Taking into account the heterogeneity of the rock masses, the site is divided into 240 permeability zones according to the locations and degree of weathering of the rocks. The calibrated permeability coefficients for the strongly weathered zones are tabulated in Table 1.

Furthermore, the dam structures are partitioned into 17 zones. The materials of the dam are classified into three groups: dominant rock filled material (dam-I), secondary rock filled material (dam-II), and drainage rock filled material (dam-III). Their permeability coefficients are the same in both horizontal directions, but the permeability in the vertical direction is lower than that in the horizontal as the rock materials were filled in the horizontal plane and compacted in the vertical direction. The permeability coefficients are chosen based on the data supplied by the engineering department (Table 1).

In addition, the reinforcement face slab and grout curtain are treated as concrete having isotropic permeability coefficients (Table 1).

\section{Analyses of 3D seepage flow}

The forthcoming sections will report on the results and findings of the analyses for natural seepage before and after impounding of the water. As fault $F_{8}$ is considered to be the major geological structure affecting groundwater flow, analyses are also carried out to study its effects.

\section{Simulation of seepage flow before impounding of water}

The aim of this simulation is to calibrate the input hydraulic parameters such as the coefficients of permeability and the rainfall infiltration coefficients. The coefficients of permeability are determined by pumping and well injection tests, whereas the rainfall infiltration coefficients are determined by infiltration tests. Since the rainfall infiltration will be affected by the topography, the coefficients are varied to reflect the changes in the topography. In the present analysis, the rain infiltration coefficients are arbitrarily chosen be in the range of 0.05 to 0.08 .

The groundwater levels of the dam site were determined by carrying out measurements at 50 boreholes. The contours of the groundwater level obtained from field observation are presented in Fig. 5. On the other hand, the simulated results are depicted in Fig. 6. The results show that the observed and simulated values are in fairly good agreement in the global sense, although some localized discrepancies are noted (for example, borehole no. 101). The maximum error and the average error are about 18 and $6 \%$, respectively. The discrepancies are not unexpected in view of the fact that it is not possible to simulate every detail of the discontinuities, and therefore, the model may fail to simulate some localized effects. Nevertheless, it is believed that the present model would be of sufficient accuracy in predicting the groundwater flow in the dam site.

\section{Prediction of seepage flow after impounding of water}

The groundwater flow in the dam site under working conditions is also studied. The groundwater level contours with a high water level in the reservoir is shown in Fig. 7. One 
Fig. 9. Comparison of the estimated groundwater levels in the cross-section below the dam for two different permeability values of the fault $F_{8}$ with a high water level in the reservoir.
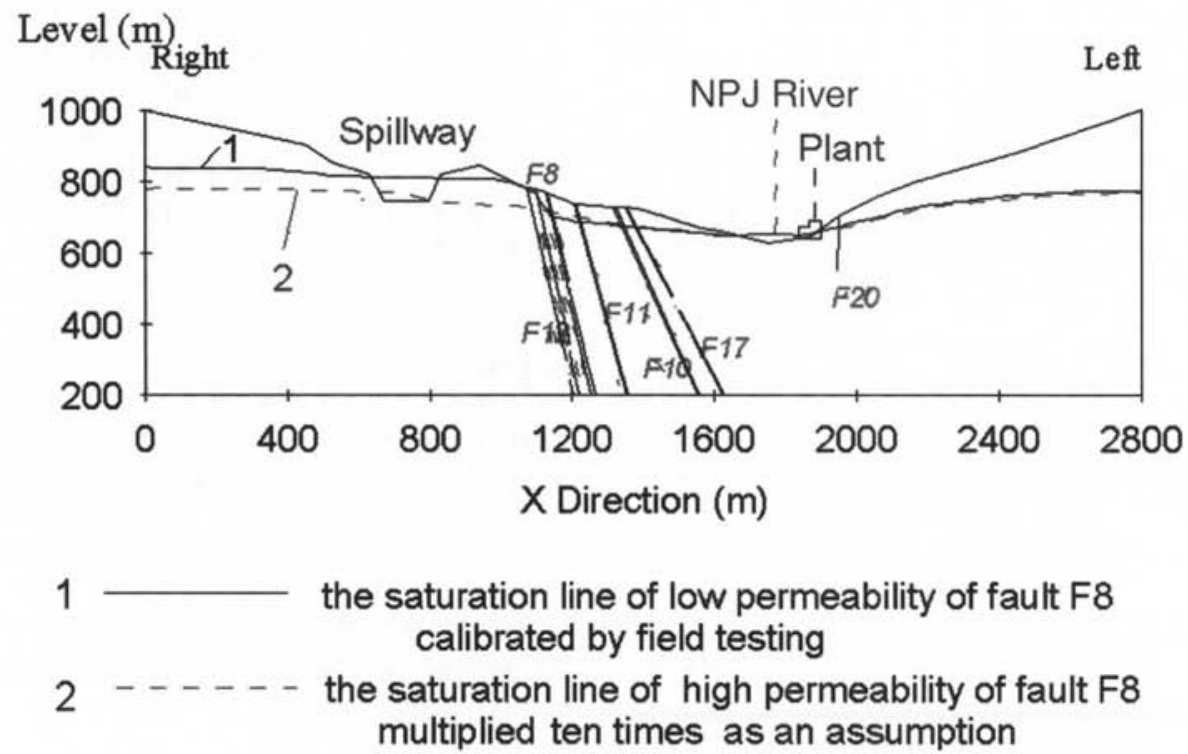

can note that the groundwater table is significantly altered after the completion of the project. The groundwater levels in the bedrock rise about $50-70 \mathrm{~m}$ whereas the levels at the two banks rise $20-30 \mathrm{~m}$. As the permeability coefficients of faults $F_{1}$ and $F_{8}$ are lower than those of the other faults, the groundwater level at the right bank is about $20-30 \mathrm{~m}$ higher than the level at the left bank. The reservoir began to store water from 1999 and the water level rose up to $779.98 \mathrm{~m}$ in October 2000. The groundwater levels at the observation wells were measured during this period. The distributions of both the measured and the predicted groundwater levels are in fairly good agreement. Measured and predicted values for some of the boreholes at the two banks of the river are listed in Table 2 (KHIDI 2000). Boreholes HW9, HW63, HW 105 , HW258, HW259, HW260, HW261, HW262, and HW263 are at the right bank, whereas boreholes HW251, HW252, HW253, HW254, HW255, HW256, and HW257 are at the left bank. However, the measured values are slightly higher than the predicted levels, and the differences are in the range of 1.25 to $13.52 \mathrm{~m}$. The reason is perhaps due to the fact that the assumed precipitation is less than the precipitation measured during this period.

When the water level at the upstream of the dam is $780 \mathrm{~m}$ (i.e., high water level of reservoir), the computed results show that the water level table falls to 665.0 and $645.9 \mathrm{~m}$ in the middle of the dam and the downstream of the dam, respectively, (Fig. 8). Such a drop in water level is mainly due to the reinforcement face slab and the grout curtain that serve as relatively impervious walls (with low permeability, $K=10^{-5} \mathrm{~cm} / \mathrm{s}$ ). Since the permeability of nonweathering rock masses is also low, the effect of the grouting curtain is not strong. Measurements were carried out in October 2000 , and the water level was determined to be approximately at $663.40 \mathrm{~m}$ in the middle of the dam. This confirms that the model can fairly accurately predict the water level in the dam.

Since the groundwater levels at the two banks are higher than the water levels in the reservoir, the possibility of reser- voir water leakage through the bedrock at the two banks is unlikely. However, leakage can take place through the dam and the foundation. The leakage flux of reservoir water is predicted under the condition of high water level, and these results are in agreement with the subsequent field measured values at different locations (Table 3 ).

\section{Role of fault $\mathbf{F}_{\mathbf{8}}$}

Fault $\mathrm{F}_{8}$ is one of the major geological structures in the dam site. Well water injection test results reveal that the permeability of fault $F_{8}$ is lower than that of the rock mass at both sides of the fault. It seems that fault $\mathrm{F}_{8}$ acts as a flow barrier on the right side of the dam. According to the original design, an extensive grout curtain along fault F8 should be constructed to prevent the groundwater table at the left side of the fault rising to a level that would endanger the slope; such an operation is fairly expensive. Therefore, a simulation was carried out to investigate the effectiveness of fault $\mathrm{F}_{8}$ as a water barrier. The results show that the variation in permeability of fault $F_{8}$ has a considerable effect on the hydraulic conditions (Fig. 9).

When the coefficient of permeability is low $(0.00033 \mathrm{~m} /$ day $)$, the fault can be regarded as an aquiclude and the head difference is large between the right side and the left side of the fault. The heads are 793.8 and $713.1 \mathrm{~m}$ above the reference datum on the right and left sides of the fault, respectively. On the other hand, the head at the right side of the fault drops to $751.4 \mathrm{~m}$, whereas the head at the left side rises to $738.3 \mathrm{~m}$ if the coefficient of permeability is high $(0.033 \mathrm{~m} /$ day). Since such an increase in the head (from 731.1 to $738.3 \mathrm{~m}$ ) at the left side of the fault is not large enough to endanger the gentle slope, the fault can serve as a barrier, and therefore, the grout curtain is unnecessary. Comparing with the results of the recently observed groundwater level, the predicted values based on low permeability are fairly close to the observed values. (See the values of HW260 and HW262 in Table 2. These boreholes are near the fault.) The differences between the predicted values us- 
ing a high permeability and the measured one are larger. Therefore, one may consider that the permeability of F8 should be within these values and probably closer to the lower value.

\section{Summary and conclusions}

An example of an application of the dual fracture model to analyze the groundwater flow for a dam site has been reported. The geology of the site is fairly complicated with a large number of major discontinuities, which dissect the rock masses into a number of blocks. These blocks also contain numerous minor discontinuities. In the model, major discontinuities constitute dominant fracture networks. Using the discrete network method, they are modeled by either $1 \mathrm{D}$, 2D, or 3D elements depending on their geometries. The blocks are modeled as heterogeneous and anisotropic continuum media. Their equivalent permeabilities are estimated from small fracture networks based on the results of geology surveys and field tests. As it is not easy to determine the equivalent permeabilities, an algorithm was also introduced for estimating such permeabilities from the field data.

The simulation of the seepage flow before and after reservoir storage has been carried out. The predicted values for the groundwater table in the middle of the dam and the leakage flux from the dam and the foundation, in general, agree fairly well with the observed values. Errors between predicted and measured values also exist, and such errors are mainly due to the simplification made in the boundary conditions, especially in the two banks. The results also show that fault $F_{8}$ can serve as a barrier to the flow of groundwater, and therefore, it is not necessary to install the curtain grout as in the original design. The predicted results are confirmed by the recently measured groundwater level.

This model shares some of the advantages of discrete network models and continuum models. It must be pointed out that the classification of the dominant fractures is relative and it depends on the scale of the region, the complexity of the geological conditions, and the extent of the geology survey. As these fractures control the flow of groundwater, it is necessary to include every large or relatively large fracture in the model.

\section{Acknowledgements}

The authors would like to acknowledge the financial support from the Research Grants Council of Hong Kong and the Hong Kong Jockey Club Charities Trust. The authors would also like to thank the two reviewers and the editor, whose comments and suggestions have enhanced the presentation of the manuscript.

\section{References}

Barenblatt, G.I., Zeheltov Iu, P., and Kochina, I.F. 1960. Basic concepts in the theory of seepage of homogeneous liquids in fissured rocks. Journal of Applied Mathematics and Mechanics, 24(5): $1286-1303$.

Cacas, M.C., Ledoux, E., Demarsily, G., Tillie, B., Barbreau, A., Durand, E., Feuga, F., and Peaudecerf, P. 1990. Modeling fracture flow with a stochastic discrete fracture network - calibra- tion and validation. 1. The flow model. Water Resources Research, 26(3): 479-489.

Carrera, J., Heredia, S., Vomvoris, S., and Hufschmied, P. 1990. Modeling of flow with a small fractured monzonitic gneiss block. In Hydrogeology of low permeability environments, International Association of Hydrogeologist, Hydrogeology: Selected Papers, 2. Edited by S.P. Neuman and I. Neretnieks. Heise, Hanover, Germany, pp. 115-167.

Carrera, J.J., and Lurdes, M.L. 2000. Mixed discrete-continuum models: a summary of experiences in test interpretation and model prediction. In Dynamics of fluid in fractured rock. Edited by B. Faybishenko. P.A. Witherspoon, and S.M. Benson. Geophysical Monograph 122, American Geophysical Union, Washington, D.C., pp. 251-266.

Dershowitz, W.S., and Einstein, H.H. 1988. Characterizing rock join geometry with joint system models. Rock Mechanics and Rock Engineering, 22: 21-51.

Dershowitz, W.S., Wallmann, P., Geier, J.E., and Lee, G. 1991. Discrete fractured network modeling of tracer migration experiments at the SCV site. SKB Report 91-23. Swedish Nuclear Power and Waste Management Co., Stockholm, Sweden.

Gomez-Hernandez, J.J., Hendricks, H.J.W.M., Sahuquillo, A., and Capilla, E. 1999. Calibration of 3-D transient groundwater flow models for fractured rock in MODELCARE. In Proceedings of the International Conference on Calibration and Reliability in Groundwater Modeling, 20-23 Sept., Eidgenossiche Technische Hochschule (Swiss Federal Institute of Technology), Zurich, Switzerland, pp. 397-405.

Herbert, A., Lanyon, J.G.G., and MacLeod, R. 1991. Modeling for the Stripa site characterization and validation drift inflow: prediction of flow through fractured rock. SKB Report 91-35, Swedish Nuclear Power and Waste Management Co., Stockholm, Sweden.

Hestir, K., and Long, J.C.S. 1990. Analytical expressions for the permeability of random two-dimensional Poisson fracture networks based on regular lattice percolation and equivalent media theories. Journal of Geophysical Research, 95(B13): 21565 - 21581 .

Hsieh, P.A., and Neuman, S.P. 1985. Field determination of the three-dimensional hydraulic conductivity tensor of anisotropic media, 1. Theory. Water Resources Research, 21(11): 1655-1666.

Hsieh, P.A., Neuman, S.P., Stiles, G.K., and Simpson, E.S. 1985. Field determination of the three-dimensional hydraulic conductivity tensor of anisotropic media, 2. Methodology and application to fractured rocks. Water Resources Research, 21(11): $1667-1676$.

KHIDI. 2000. Reports of the dam monitoring of Tianshengqiao Hydro-power Station. Kunming Hydroelectric Investigation and Design Institute (KHIDI), National Electric-power Company of China, August 2000. (In Chinese.)

Kim J.G, and Deo, M.D. 2000. Finite element, discrete-fracture model for multiphase flow in porous media. AIChE Journal, 46(6): $1120-1130$.

Long, J.C.S., and Billaux, D.M. 1987. From field data to fracture network modeling: an example incorporating spatial structure. Water Resources Research, 23(7): 1201-1216.

Long, J.C.S., and Witherspoon, P.A. 1985. The relationship of the degree of interconnection to permeability in fracture networks, Journal of Geophysical Research, 90(B4): 3087-3098.

Long, J.C.S., Remer, J.S., Wilson, C.R., and Witherspoon, P.A. 1982. Porous media equivalents for networks of discontinuous fractures. Water Resources Research, 18(3): 645-658.

Long, J.C.S., Gilmour, P., and Witherspoon, P.A. 1985. A model for steady fluid flow in random three-dimensional networks of discshaped fractures. Water Resources Research, 21(8): 1105-1115. 
Louis, C., and Wittke, W. 1971. Experimental study of water flow in jointed rock massif, Tachien Project Formosa. Géotechnique, 21(1): $29-36$.

Munjiza, A., Latham, P.J., and Andrews, K.R.F. 2000. Detonation gas model for combined finite-discrete element simulation of fracture and fragmentation. International Journal for Numerical Methods in Engineering, 49(12): 1495-1520.

National Research Council. 1996. Rock fractures and fluid flows: Contemporary understanding and applications. National Academy Press, Washington, D.C.

Neuman, S.P., and Depner, J.S. 1988. Use of variable scale pressure test data to estimate the $\log$ hydraulic conductivity covariance and dispersivity of fractured granites near Oracle, Arizona. Journal of Hydrology, 102(1-4): 475-501.

Oda, M. 1985. Permeability tensor for discontinuous rock masses. Géotechnique, 35(4): 483-495.

Pruess, K., and Narasimhan, T.N. 1985. A practical method for modeling fluid and heat flow in fractured porous media. Society of Petroleum Engineers Journal, 25(1): 14-16.

Singhal, B.B.S., and Gupta, R.P. 1999. Applied hydrogeology of fractured rocks. Kluwer Academic Publishers, The Netherlands.

Streltsova, T.D. 1976. Hydrodynamics of groundwater flow in fractured formation. Water Resources Research, 12(3): 405-414.

Sudicky, E.A., and McLaren, R.G. 1992. The Laplace transform Galerkin technique for large scale simulation of mass transport in discretely fractured porous formations. Water Resources Research, 28(2): 499-514.

Tian, K.M., and Wan, L. 1989. Research and evaluation of anisotropy permeability of fractured media. Xueyuan publish Press. (In Chinese.)
Tsang, Y.W., Tsang, C.F., and Hale, F.V. 1996. Tracer transport in a stochastic continuum model of fractured media. Water Resources Research, 32(10): 3077-3092.

Tsinghua University. 1998. Report of three-dimensional seepage flow in fractured rocks and dam of Tianshengqiao Hydropower Station, Beijing, China. August 1998. (In Chinese.)

Wang, E.Z. 1991. A study on the models of the groundwater movement in fractured networks. Modeling in Groundwater Resources. In Proceedings of the International Conference on Modeling Groundwater Flow and Pollution, Nanjing, China, 2226 April 1991. Edited by Y.Q. Xue and J. Bear. Nanjing University Press, China, pp. 414 421.

Wang, E.Z. 1993. The model of groundwater flow in quasi-dualporosity medium. In Proceedings of the First Conference of Chinese Post-Ph.D., Beijing, China, 20-25 June 1993. Edited by E.B. Feng. National Defense Industry Press. Beijing, China, pp. 2056-2060. (In Chinese.)

Wang, E.Z., and Yang, C.T. 1992. The mathematical model of groundwater flow in fractured networks and non-connect fractured networks. Chinese Journal of Hydrogeology and Engineering Geology, 19(1): 12-15. (In Chinese.)

Wang, E.Z., Wang, H.T., and Sun, Y. 1997. Study on threedimensional flow model of discrete fracture networks. Chinese Engineering Mechanics, 14 (Suppl.2): 520-525. (In Chinese.)

Wang, E.Z., Wang, H.T., and Sun, Y. 1998. Study on the seepage flow in dual fracture systems. Chinese Journal of Rock Mechanics and Engineering, 17(4): 400-416. (In Chinese.)

Wilson, C.R., and Witherspoon, P.A. 1974. Steady state flow in rigid networks of fractures. Water Resources Research, 10(2): $328-339$. 